\title{
JURISPRUDENCIA AMBIENTAL EN CANARIAS (SEGUNDO SEMESTRE 2020)
}

\author{
ADOLFO JIMÉNEZ JAÉN \\ Profesor titular de Derecho Administrativo \\ Universidad de Las Palmas de Gran Canaria
}


Sumario: 1. Vertidos. 2. Medidas cautelares adoptadas en función del principio de precaución.

\section{1.- Vertidos}

El Juzgado no 1 de lo Contencioso-Administrativo de Santa Cruz de Tenerife en su Sentencia de 29 de enero desestima el recurso interpuesto frente a la resolución 731/2017 de fecha 12 de mayo de 2017 dictada por el AlcaldePresidente del Ayuntamiento de Arafo por la que se acordó el cese inmediato del vertido que se realiza a través del emisario submarino del Polígono Industrial del Valle de Güimar hasta tanto se obtenga autorización definitiva o en su caso, provisional, adoptando las medidas pertinentes para llevar a cabo dicho cese del vertido.

Dicha Sentencia considera que el cese del vertido acordado en la resolución impugnada no supone inicio de expediente sancionador, sino mera ejecución por parte del Ayuntamiento de Arafo de una resolución dictada por la APMUN que era inmediatamente ejecutiva y que conminaba a las propietarias del emisario submarino a la legalización del vertido y al cese del mismo en el plazo de un mes. Los Ayuntamientos demandados estaban obligados a cumplir la orden de cierre, sin perjuicio de recurrirla. No concurren las causas de nulidad de pleno derecho alegadas por la asociación recurrente por cuanto el cumplimiento de la orden de legalización y cierre no supone la tramitación de un expediente administrativo por parte de los Ayuntamientos en cuestión.

La representación de la Asociación de Propietarios y Empresarios del Polígono Industrial del Valle de Güimar interpuso recurso de apelación contra dicha resolución interesando que, estimando en todas sus partes el recurso, se acordase dictar Sentencia estimatoria del Recurso de Apelación interpuesto y, por ende, de la demanda presentada.

La Sentencia 82/2020, de 28 de febrero de 2020, resuelve dicho recurso. En sus alegaciones los apelantes habían alegado que se había adoptado una sanción sin seguir el procedimiento legalmente establecido 
En cambio el Tribunal Superior estima que "ha de rechazarse la consideración de que el Ayuntamiento de Arafo haya iniciado un procedimiento sancionador que culmina con la resolución que acuerda el cierre del emisario, sin trámite de audiencia ni alegaciones o prueba. Y ello pese a que "el Ayuntamiento de Candelaria sí haya optado por realizar dicho trámite de audiencia con respecto a la entidad aquí apelante, lo cierto es que ello era innecesario, tal y como vamos a resolver en el recurso de apelación seguido ante este mismo Tribunal con el $n^{\circ}$ 277/2019 que se delibera en el mismo día".

En consecuencia, según la sentencia "No hay infracción alguna a la que haga referencia la resolución aquí impugnada, ni posible sanción que pudiera recaer sobre la entidad apelante. Lo que sí hay es una decisión adoptada por el Ayuntamiento en el ejercicio de sus competencias y en relación con una instalación de la que es titular. Que ello puede afectar a la entidad apelante y que puede ostentar interés no se niega, pero no deriva de lo acordado por el Ayuntamiento, sino del cese de los vertidos no autorizados que impone la ley $y$ ejecuta la APMUN".

La segunda alegación tiene que ver con la adopción o no por parte de la Agencia de Protección del Medio Urbano y Natural (APMUM).

Respecto de este punto, el Tribunal señala que "ha de estar de acuerdo con el hecho de que no se han adoptado ningún tipo de medidas al respecto de forma directa por la APMUN", si bien matiza que "ello, ni legaliza los vertidos no autorizados, ni permite mantener su realización sine die".

Los recurrentes habían alegado que la Agencia de Protección del Medio Urbano y Natural (APMUN). Según los recurrentes, el cese de los vertidos no podía derivar de la actuación de la APMUN, ya que, según los recurrentes, "/o pretendido era que se obtuviera la autorización del vertido durante la tramitación del procedimiento, no necesariamente en el plazo de 1 mes, porque el cese de los vertidos ilegales se realizaría mediante la obtención de la autorización y porque no se requiere para que se cierre el emisario en un mes, sino que se ponga en marcha la solicitud de autorización en el plazo de un mes".

Así, según la sentencia el "cese de los vertidos que se deriva de la resolución de la APMUN en realidad no deriva de la misma" Para el Tribunal lo relevantes es 
que no es posible "realizar vertidos de tierra al mar sin autorización, así lo establece la Ley 22/1988, de 28 de julio, de Costas en su art. 7 ("Artículo 571. Todos los vertidos requerirán autorización de la Administración competente, que se otorgará con sujeción a la legislación estatal y autonómica aplicable, sin perjuicio de la concesión de ocupación de dominio público, en su caso.") y en cuanto al emisario submarino el mismo, al no estar ya vigente la autorización de vertidos establecida en su día, ya no cuenta con autorización para ocupar el dominio público marítimo terrestre (art. 58.4 de la Ley de Costas "4. La extinción de la autorización de vertido, cualquiera que sea la causa, llevará implícita la de la inherente concesión de ocupación del dominio público marítimo-terrestre.")”.

La inexistencia de autorización para el vertido que se está realizando y para la ocupación del dominio público por parte del emisario submarino, implica el inmediato cese de dichas actividades ilegales.

De la jurisprudencia citada por las partes en sus respectivos escritos, claramente, la que más se acerca al presente supuesto y la que ha de asumirse es la Sentencia del Tribunal Supremo que cita el Ayuntamiento de Arafo, dictada por la Sala 3 $3^{a}$, sec. $4^{a}$, de fecha 06-04-2016 (rec. 2650/2014) y otras dictadas ese mismo día, especialmente porque reflejan una situación de problemas competenciales similares a los que aquí se plantearon inicialmente entre las diversas administraciones implicadas y que el TS zanja señalando: "Las limitaciones derivadas de las conductas o comportamientos de otros, no impiden poner en funcionamiento o iniciativa todas aquellas competencias propias que permitan reaccionar contra las situaciones anormales y dar lugar a un restablecimiento de la legalidad.".

En consecuencia, concluye la sentencia “Lo acordado por el Ayuntamiento de Arafo entra dentro de sus competencias y no precisaba de la incoación de un expediente administrativo autónomo con audiencia de los interesados. En este mismo sentido nos vamos a pronunciar en el recurso de apelación que pende ante este Tribunal con el n²77/2019".

\section{2.- Medidas cautelares adoptadas en función del principio de precaución.}

La sentencia del Tribunal Superior de Justicia de Canarias 74/2020, de 18 de febrero de 2020, analiza la impugnación de la sentencia del Juzgado de lo 
Contencioso- Administrativo no 4 de esta Provincia, dictada en el procedimiento 247/2018 por la que se estima el recurso contra la Resolución no 817/2018, de 25 de mayo, del Alcalde Presidente del Ayuntamiento de Arafo, que acordó el cese inmediato de vertidos a la red municipal de saneamiento de aguas residuales así como al de pluviales por parte de la empresa EXCLUSIVAS DITAYO S.L, ubicada en el Manzana F, Parcela 6, del Polígono Industrial del Valle de Güímar.

La Resolución no 817/2018, de 25 de mayo, del Alcalde Presidente del Ayuntamiento de Arafo, que acordó el cese inmediato de vertidos a la red municipal de saneamiento de aguas residuales así como al de pluviales por parte de la empresa E.D. S.L, ubicada en el Manzana F, Parcela 6, del Polígono Industrial del Valle de Güímar, como medida provisional y sin que la misma tenga el carácter de sanción, de conformidad con el informe emitido por el Arquitecto Técnico Municipal, de fechas 27 de noviembre de 2017 y 11 de abril de 2018, acreditativo de que por parte de la citada empresa se están vertiendo aguas residuales, sin que conste presentación alguna en cuanto a la tipología de vertidos según requerimiento efectuado mediante Resolución no 1927/2017, de 30 de noviembre.

Según los recurrentes, teniendo en cuenta la naturaleza de los vertidos, propia de desagües domésticos, "no se indica en la resolución recurrida por la Administración en qué consiste el incumplimiento por esta empresa de la normativa de desagües. No habiendo un examen de la naturaleza de los desagües producidos por la empresa recurrente, ni análisis químicos que justifiquen excesos en la química del agua, como ha ocurrido con otras empresas del Polígono, no se considera debidamente motivada la ilegalidad de los vertidos". En definitiva, según los recurrentes, "la resolución administrativa no justifica con una motivación debida la decisión de ordenar el cese inmediato de vertidos a la red municipal de saneamiento de aguas residuales, y por lo tanto causa indefensión por falta de garantías debidas. Procede anular el acto administrativo recurrido".

Pues bien, según el Tribunal Superior, "el análisis de una cuestión como la litigiosa debe partir, tanto en primera como en segunda instancia, del principio de precaución o cautela, dado que atañe a la protección del medio ambiente". 
La sentencia toma como punto de partida la evolución del principio de precaución en la política y el derecho ambiental de la Unión Europea:

"Procedente de la política medioambiental alemana ("Vorsorgeprinzip"), se positiva hoy en el actual Tratado de Funcionamiento de la Unión Europea, en su artículo 191, apartado 2.Por otra parte, numerosos pactos internacionales adoptados en el ámbito de la Organización de las Naciones Unidas (ONU), hacen referencia directa o indirecta al mismo principio, comenzándose a partir de mediados de la década de los años 80 del pasado siglo XX a incluirse el "principio de precaución" en instrumentos internacionales en materia ambiental: Declaración de Helsinki sobre Medio Humano (1972), Declaración de Río sobre Medio Ambiente y Desarrollo (1992), Agenda 21 (1992), Convención de Londres sobre Contaminación del Mar por Hidrocarburos (1954) sustituida por la Convención de Londres sobre la Prevención contra la Contaminación por Buques (1973), Convención sobre Cambio Climático (1992), Convención sobre Biodiversidad. En todo caso, debe recordarse como tratado internacional que más ha avanzado en la configuración de la obligación de cautela el Protocolo de Montreal sobre Bioseguridad (2000), adoptado en el marco de la citada Convención sobre Biodiversidad".

A continuación, analiza la jurisprudencia europea, que ha reconocido este principio en las SSTJCE, asunto National Farmers' Union (C-157/96) y asunto Reino Unido/Comisión ( C- 180/96), ambas de 5 de mayo de 1998.

Así, en el asunto National Farmers ? Union, el TJCE "reconoce que ha de admitirse que cuando subsisten dudas sobre la existencia o alcance de los riesgos para la salud de las personas, las Instituciones pueden adoptar medidas de protección sin tener que esperar a que se demuestre plenamente la realidad y gravedad de tales riesgos. En los mismos términos se pronuncia también el TJCE en el asunto "Reino Unido/Comisión"

Por su parte, las SSTPI, asunto Alpharma ( T-70/99) y asunto Pfizer ( T-13/99), ambas de 11 de noviembre de 2002, "consideran que el principio de cautela es 
uno de los principios en los que se basa la política de la Comunidad en el ámbito del medio ambiente".

Pues bien, de estas sentencias extrae el Tribunal sin dificultad "el principio general de que cuando subsisten dudas científicas sobre la existencia de riesgos para la salud humana o sobre su alcance, las instituciones comunitarias pueden adoptar medidas de protección en virtud del principio de cautela sin tener que esperar a que se demuestren plenamente la realidad y la gravedad de tales riesgos".

A ello añade el Tribunal que la "fuerza del principio de precaución o cautela queda perfectamente reflejada en el Auto del Tribunal de Primera Instancia asunto Solvay Pharmaceuticals BV/Consejo de la Unión Europea ( T-392/02 R,"), de 11 de abril de 2003, el cual recuerda que de la jurisprudencia se desprende que sólo puede adoptarse una medida preventiva cuando la existencia y el alcance del riesgo no hayan sido plenamente demostrados mediante datos científicos disponibles en el momento en que se adopte dicha medida". Y considera que debe atribuirse incontestablemente un carácter preponderante a las exigencias ligadas a la protección de la salud pública frente a las consideraciones económicas, llegando a afirmar que cuando una institución comunitaria invoca la existencia de un serio riesgo para la salud pública, el juez de medidas provisionales debe inclinarse de manera casi inevitable, pese a su soberanía formal en la ponderación de los intereses, a favor de la protección de ésta. Los argumentos sobre pérdidas económicas de la empresa o pérdida de puestos de trabajo, por tanto, ceden de manera irremediable ante el interés general encarnado en el principio de cautela.Y en la STJCE, asunto MalaguttiVezinhet (T-177/02), de 10 de marzo de 2004, en la que el Tribunal se pronuncia sobre la reparación del perjuicio que la demandante alega haber sufrido como consecuencia de la difusión por la Comisión de un mensaje de alerta rápida en el que se informaba de la presencia de residuos de plaguicidas en manzanas de origen francés, el tribunal afirma que dado que se trataba de prevenir riesgos para la salud de los consumidores, era suficiente con que la Comisión se encontrara ante datos plausibles que indicaran la existencia de un vínculo entre la demandante y las manzanas que se habían considerado peligrosas. Por lo que, en la medida en que subsistan dudas, es preciso señalar que, según el 
principio de cautela, que rige en materia de protección de la salud pública, la autoridad competente puede estar obligada a adoptar las medidas adecuadas con vistas a la prevención de determinados riesgos potenciales para la salud pública, sin tener que esperar a que se demuestren plenamente la realidad y la gravedad de tales riesgos. Y añade que si fuese preciso esperar a los resultados de todas las investigaciones necesarias antes de adoptar tales medidas, se estaría privando de eficacia al principio de cautela. Por lo que la demandante, que ha sido víctima del sistema de alerta creado para proteger la salud humana, ha de aceptar las consecuencias económicas negativas, ya que debe atribuirse una importancia preponderante a la protección de la salud pública frente a las consideraciones económicas.

En definitiva, el Tribunal concluye que "que en materia de medio ambiente la prueba debe poner su seña de identidad en demostrar la existencia del riesgo de insalubridad que se detecta en el vertido de aguas, tanto las no canalizadas, que discurren externamente por donde no deberían, ilo cual siempre implica riesgo de insalubridad como las canalizadas que elevan los indicies de contaminación en el mar". 